\title{
Politeness and Discourse Functions in Doctor-Patient Verbal Interactions at the University College Hospital, Ibadan, Nigeria
}

\author{
Adewale Kazeem Ayeloja ${ }^{1 *}$, Taofeek Olanrewaju Alabi ${ }^{2}$ \\ ${ }^{I}$ Ph.D. student at University of Ibadan, Oyo State, Nigeria \\ ${ }^{2}$ Department of General Studies, The Federal Polytechnic, Ado-Ekiti, Ekiti State, Nigeria
}

*Corresponding Author: Adewale Kazeem Ayeloja, Ph.D. student at University of Ibadan, Oyo State, Nigeria

\begin{abstract}
Doctor-patient verbal interactions face some communication challenges as a result of the sensitive nature of communication in medical contexts. A number of discourse-analytic studies have been carried out on doctor-patient verbal interactions, focusing pertinent pragmatic concerns in medical contexts, but with insufficient attention paid to politeness and its discourse benefits. Therefore, this study explores language use in doctor-patient verbal interactions with the objective of discovering the specific face-threatening acts and politeness maxims employed to enhance diagnostic communication at the University College Hospital, Ibadan, Nigeria. The theoretical framework adopted for this study is a synthesis of Brown and Levinson's politeness theory and Leech's politeness maxims. Fifty tape recordings of doctor-patient recordings were made at the University College Hospital, Ibadan, Nigeria. A total of twenty-five interactions were purposively selected because of their strategic content from the data got at the hospital. The data were then orthographically transcribed and analyzed qualitatively. The various politeness elements perform a number of communicative functions. FTA with redress corrects unwholesome health practices; FTA without redress tactfully obtains medical data for diagnosis; tact maxim expresses compassion; generosity maxim offers advice; sympathy maxim offers guidance, and the ethical positivity tendency opens up talks. Knowledge of these elements of politeness and their discourse functions are therefore crucial to a better comprehension of clinical discourse in Nigeria.
\end{abstract}

Keywords: Politeness, Medical Context, Politeness Maxims, Face-Threatening Acts, Diagnostic Communication

\section{INTRODUCTION}

Discourse is crucial to medical communication as a significant part of diagnosis is carried out through conversation. Doctors and patients interact for the purpose of investigating patients' ailments and proffering appropriate medical solutions to them. During clinical interview, a number of hindrances are encountered in the process of diagnosing the patients' ailments. Given the situation, doctors are constrained to employ the best communication methods as required by the diagnostic context. Therefore, effective communication on the part of doctors, nurses and patients facilitates the attainment of the objectives of medicine: diagnosis, prevention and cure.

Research on communication in medical settings has emerged from a number of disciplines such as medical sociology, medical anthropology, medical ethno methodology, social psychology, and linguistics, including clinical linguistics. Clinicians too churn out a considerable number of researches (Martin, 2014). All the disciplines put forth their own specific methodological, epistemological and ontological assumptions to the study of themes such as the social institution of medicine, the health beliefs of participants in a consultation and their embeddedness in a particular cultural value system, the communication between healthcare providers and patients and that amongst healthcare providers (Martin, 2014).

Good communication has been recognized as the basis for making a diagnosis, laying a course of treatment, giving advice and dealing with the emotional implications of diseases. This awareness helps to explain why most research on medical discourse has concentrated on doctor-patient interactions. The last forty years have witnessed significant growth in interest amongst sociolinguists and discourse analysts in doctor-patient communication as a field of inquiry. A review of the literature however reveals that the boundaries of this field of investigation transcends such dyadic or multi- 
party consultations and, increasingly, include alongside front stage encounters with patients so-called backstage activities (Sarangi and Roberts, 1999) involving inter alia interaction between various providers within a particular institutional context (Martin, 2014).

\subsection{Theoretical Framework}

The theoretical framework adopted for this study is a synthesis of Brown and Levinson's politeness theory $(1978,1987)$ and Leech's $(1983)$ politeness maxims. These theories are considered apt for the study because of their explication of the face-threatening acts (FTAs) and politeness maxims respectively, which are the main analytical tools for this study.

\subsection{Politeness Principle}

Politeness is the practical application of good manners or etiquette. It is a culturally defined phenomenon, and therefore what is considered polite in one culture can sometimes be quite rude or simply eccentric in another cultural context. It is also a central force in communication, arguably as basic as the pressure to be truthful, informative, relevant and clear (Grice, 1975; Brown and Levinson, 1978; Leech, 1983). Natural languages provide many different means for encoding politeness and, in conversation we choose where and how to use these devices. Odebunmi (2003, p.76) citing Kaplan (1999) opines that people like to be respected and identifies honorifics and other politeness markers like: please. Politeness markers are intimately related to the power dynamics of social interactions and are often a decisive factor in whether those interactions go poorly or well.

Brown and Levinson's (1978) politeness model is founded on the notions of "face" offered by Goffman and 'conversational logic proposed"' by Grice. 'Face" refers to wants of every person: (1) to be approved by others (positive face), (2) to have his/her actions or thoughts unimpeded by others (negative face). The face-saving view of politeness places emphasis on the wants of the participants in a given interaction rather than on the interaction itself or the norms operating in society. Face is "something that is emotionally invested, and can be lost, maintained or enhanced, and must be constantly attended to in interaction"' (Odebunmi, 2003).

In performing an apology, the speaker acknowledges the addressee's face-want not to be offended. Apologizing is face-threatening for the speaker and face-saving for the addressee. In contrast with negative politeness, positive politeness is an involvement-based approach made by the speaker to ratify, understand, approve of, and admire the positive image of the addressee (Odebunmi, 2003). Brown and Levinson (1987:75) refer to the function of positive politeness strategies as one of minimizing the potential threat of an FSA by assuring the addressee that the speaker (S) has a positive regard for him or her and wants at least some of the wants of the addressee. Holmes (1995) claims that apologies can also function as positive politeness strategies for addressee (A) since (S) supports A's need for positive feelings and affirmation from others. Examples of an apology act functioning as positive politeness are: (1) a speaker admitting that the addressee is right to feel offended by the infraction; (2) a speaker demonstrating his commitment to remedying the situation and appeasing the addressee through an offer of repair and (3) a speaker using deference markers such as titles or forms of address (Dr. Sir, Ma'am) or formal verb forms and corresponding pronouns (T-V forms). Brown and Levinson's (1978: 74) theory assumes that negative politeness is the universally preferred approach to facework: 'It is safer to assume that $\mathrm{H}$ (hearer) prefers his peace self-determination more than he prefers your expression of regard, unless you are certain to the contrary." In agreement with other scholars (Scollon, 1981; Placencia, 1992; Nwoye, 1992), this is a valid assumption.

Kasher (1976:201) opines that the Gricean idea that "'in all stages of any conversation, it is always possible to identify a joint purpose shared by all those in conversation"' is mistaken. He postulates that it is probable for interlcutors not to have mutual aims, and adds that every participant has the right to alter the direction as they deem fit within certain limits. Kates (1980) holds the vista that the Gricean maxims are not achievable as most speakers not only disregard this rule of cooperation but are not in any provable sense cognizant of it. Subjectively, the criticisms of the Gricean maxim merely reduce their universal applicability. They do not render them totally incompetent. Geoffrey Leech's (1983) politeness principle, even though another principle, beautifully complements the Gricean cooperative principle. This idea can be illustrated thus:

A: The classrooms, laboratories and libraries will be renovated. 
B: $\quad$ Surely, the classrooms will be renovated.

Obviously, B's reply violates the quantity maxim. His contribution suggests only the classrooms will be renovated. By merely alluding to classrooms, however, he has reduced the politeness principle to forefend triggering offence. B's intention has therefore constrained his utterance. Irony Principle -a subcategory of the politeness phenomenon- describes a second order principle. It states thus:

If you must cause offence, at least, at least, do so in a way which doesn't overly conflict with the PP, but allows the hearer to arrive at the offensive point of your remark indirectly, by way of implicature. (Leech 1983:82)

Another example for consideration:

Jane: David has broken your chair.

Debby: (obviously angered) Oh. Beautiful!

The implicature from B's contribution in the above conversation is polite, the meaning is impolite.

It is salutary to also talk briefly about deference in our discussion of politeness, but it is distinct. Deference is exhibited when others are accorded respect as a result of being older, having a greater status etc., and it is incorporated into the world languages. For instance, Yoruba is filled with honorifics that are used as markers of respect to address people with greater age or status, strangers or peers. During conversation between peers, honorifics are usually engaged by the two parties in conversation to show respect. However, it is used more in conversations between women than men. In English Language, words such as 'Sir' and 'Madam' are employed to show deference. In addition, address terms like: 'doctor', engineer', 'professor', 'pastor', 'evangelist' are used to show status differential. However, unless the norms of honorifics are violated, for instance, if someone always addressed as 'evangelist' is suddenly addressed by their first name, deference is not pragmatically relevant. Thus, deference tilts more towards sociolinguistics than pragmatics as a concept (Odebunmi, 2003).

However, Dillian et al (1985), Thomas (1986), Brown and Levinson (1987), and Frazer (1990) have observed some weaknesses in Leech's approach to the politeness phenomenon. They have claimed the maxims to be inelegant. Therefore, it is salutary to adopt Thomas'(1995) reconciliation of the issues by seeing Leech's ideas as 'a series of social-psychological constraints influencing, to a greater or lesser degree the choices made within the pragmatic parameters" but not as maxims. Therefore, Leech's maxims will be treated as factors, even though they will still be referred to as maxims for easy reference. In order to show politeness, speakers in a speech situation observe the following maxims (Leech 1983: 132):

- Tact maxim (in impositives and commissives): (a) Mininmize cost to other [(b) Maximize benefit to other.

- Generosity maxim (in impositives and commissives): (a) Minimize benefit to self [(b) Maximize cost to self.

- Approbation maxim (in expressives and assertives): (a) Minimize dispraise of other [(b) Maximize praise of other.

- Modesty maxim (in expressives and assertives): (a) Minimize praise of self (b) Maximize dispraise of self.

- Agreement maxim (in assertives): Minimize disagreement between self and other [(b) Maximize agreement between self and other.

- Sympathy maxim (in assertives): a) Minimize apathy between self and other [(b) Maximize sympathy between self and other.

- Polyanna Principle states that people prefer to look on the bright side of life rather than on the gloomy side of it. This is done through the deployment of euphemisms, minimizers and relexicalizations to handle offensive topics, using pleasant or unoffensive expressions. 


\subsection{Politeness Principle and Face-Threatening Acts}

The politeness principle (PP) resulted from the weaknesses observed in the Cooperative Principle (CP). Politeness principle has a higher regulative value than cooperative principle (Leech 1983: 82). Politeness engenders smooth continuation of communication in a manner that cordiality is assured. He however argues that both PP and CP have relative overriding tendencies. Sometimes, PP overrides $\mathrm{CP}$, and the other way round.

Politeness can be observed in situations of social distance or closeness as the means by which we "show awareness of another person's face". Yule (1996:60) technically defines face as " the public self-image of a person. Odebunmi (2003) puts it differently as the emotional and social feeling of self which an individual has and expects others to recognize.

Face can be categorized. Deference or respect is the first example, and it operates in a situation of social distance e.g., the relationship between a bus driver and his conductor, or the age respect between a child and the mother. The second type of face is friendliness, camaraderie or solidarity that occurs in social closeness. This is largely found among equals. Everybody wants his/her face to be respected irrespective of the personality concerned. Thomas comments thus:

Face, in the approach of politeness is an individual's feeling of self-worth or self-image: this image can be damaged, maintained or enhanced through interaction with others. (1995 p.169 cited in Odebunmi, 2003)

Therefore, face may be positive or negative. There is positive face when a person desires respect, approval, liking and appreciation from others. On the other hand, there is negative face when a person desires to act independently without imposition by others. It is worthwhile to reiterate that everyone wants their face wants to be met. The individual is said to have his/her face saved when this happens, but when the reverse is the case, his/her face is said to be threatened. All these events are referred to as face-threatening acts (FTAs) (Odebunmi, 2003). Face-threatening acts are illocutionary acts that are liable to damage or threaten H's positive or negative face. This sometimes results when $\mathrm{H}$ is insulted or when what $\mathrm{H}$ holds dear is disapproved of or when H's freedom is restricted. Sometimes too, might potentially cause damage to the speaker's own positive or negative face (Odebunmi, 2003).

It is however probable to reduce the damage that S's act may cause to H's face by adopting certain strategies. To choose the suitable strategy, speaker has to assess the size of the FTA, and calculate the FTA on the basis of parameters of power (P), distance (D) and rating of imposition. The stated factors influence the strategies adopted. The strategies are: (a) performing the FTA on record without redressive action, (b) performing the FTA on record using positive politeness, (c) performing the FTA on record using negative politeness, (d) performing the FTA using off-record politeness and (e), not performing the FTA (Thomas 1995). All of them are discussed in turn below.

\subsection{Performing an FTA without Redress}

According to Odebunmi (2003), this performance of the FTA is also described as bald-on-record. The FTA is performed when certain external factors constrain a person from speaking directly. Situations of emergency or when someone is working against time are some examples, between the speaker and the hearer, $\mathrm{S}$ decides to make his/her request on-record if he/she reckons that the FTA is in the best interest of H. But when the power differential is great, the FTA is sometimes not mitigated, irrespective of imposition rating. In such situations, the powerful participants do use indirectness. Generally, bald-on record acts employ imperatives which might be accompanied by mitigating devices that soften the imposition; for example, 'please", ' would you?', 'could you explain why you should not be disciplined?' Yule (1996) opines that bald-on -record expressions go in line with speech situations which Speaker an assumption of power over Other and which make him/her have the tendency to want to control the behaviour of Other through words.

\subsection{Performing an FTA with Redress (Positive Politeness)}

In discussing Brown and Levinson's approach of face management, Thomas (1995) observes that sometimes when we speak, we may orient ourselves towards an individual's positive face, and employ positive politeness that appeals to H's desire to be liked and approved of. There is equality in the politeness expressed here with Leech's (1983) principles of politeness like: 'seek agreement', 
"avoid disagreement", 'be optimistic", "'give sympathy". Because these features are very positive in nature, they can tremendously save H's face in interaction. In spite of the unsavoury preceding content of most queries, dismissal letters and warning letters written globally, it is not uncommon to see such letters end with "Thank you'. In some other cases, unpleasant situations are presented euphemistically (Odebunmi 2003).

\subsection{Performing an FTA with Redress (Negative Politeness)}

Negative politeness is achieved through the deployment of conventional politeness markers, deference markers as well as by minimizing imposition. Examples include: salutation, indirect conventionality, hedging etc.. Brown and Levinson (1978) offer ten strategies for performing an FTA with redress (negative politeness) i.e: 'be conventionally indirect", "hedge", "minimize imposition", "'admit the impingement and beg forgiveness, "use points of view distancing", " go on record as incurring a debt" etc. For example, in several commercial centres in Nigeria, particularly where the managers are literate, expressions like: "No credit, come tomorrow" are common. This means that credit facilities are not available for any purchaser regardless of his/her relationship with the management. Warning notices targeting large number of readers use negative politeness (Thomas, 1995).

\subsection{Performing an FTA Using Off-Record Politeness}

There are fifteen strategies for performing off-record politeness. Some examples are: "give hints", "use metaphors", "' be ambiguous or vague"' etc. (Brown and Levinson, 1978). Most of the instances of this face act type largely adopt Searle's preparatory condition. A number of practical examples can be cited from queries resulting from insubordination and dereliction of duty e.g.: This is not the first time of such report (Odebunmi, 2003).

\subsection{Non-Performance of FTA}

Thomas (1995) observes this happens when something appears so "potentially face threatening that one does not say it". Tanker (1992) explains two ways of avoiding saying anything:

- OOC-genuine: $\mathrm{S}$ does not perform a speech act, and genuinely intends to let the matter remain closed. She or he does not intend to achieve the perlocutionary effect.

- OOC-strategic: $\mathrm{S}$ does not perform a speech act, but expects to infer his or her wish to achieve the perlocutionary effect.

\section{Methodology}

One hundred tape recordings of doctor-patient verbal interactions were made at the University College Hospital (UCH), Ibadan, Nigeria. Fifty of them were purposively sampled based on their strategic content, making twenty-five from each hospital. The texts were orthographically transcribed. The elements of face-threatening acts (FTAs) and politeness maxims in the data were identified, and the discourse function of each was also pinpointed. The data were subjected to discourse analysis. The subject was restricted to doctors and patients alone, and an ethical approval was obtained to collect the data used for the study.

\section{Data Analysis AND Discussion}

Politeness was realized in the data by FTA without redress and FTA with redress (positive politeness) in the data, using frank talk, courteous expressions, reprimand, direct and indirect expressions. They were used after the doctors had concluded their diagnoses. Examination of the deployment of politeness was undertaken here to reveal how diagnoses were presented in a courteous manner and how patients' face was threatened without redress and with redress. In addition, efforts were made to study how the deployment of the face-threatening acts and politeness maxims aided the communication.

\subsection{Face-Threatening Act Without Redress: Being Factual, Checking And Correcting Unwholesome Health Practices}

Face-threatening acts without redress were realized by frank talk, courteous expressions and reprimand in the data. Here, we examine how their deployment aided the discourses. We consider the following extracts: 


\section{Extract 1}

BACKGROUND: After diagnosing Pt. (patient) with hepatitis B, Doc. (doctor) counsels Pt. on the importance of getting his wife tested to know her status for appropriate medical intervention, if necessary.

Doc.: Encourage her. We can't force anyone to do any test.

Pt.: Alright. She's a cool-headed person.

Doc.: Does she know about your hepatitis status?

Pt.: Yes. I told her about it.

Doc.: Since there is nothing to hide, let her also do the test. Then if she is negative, then she can take immunization, and she will be protected for life. You understand.

Pt.: Yes.

Doc.: And if she tests positive, there is no problem.

Pt.: You mean there is a vaccine for it?

Doc.: Yes. There is a vaccine against hepatitis. Anybody that is hepatitis B negative can take a vaccine - three doses. If you come first, we give you one. Then, in a month's time, we give you another one, and then in six month time, we give you another one. Those three doses will give you a life-time immunity. So, if she's negative, let her get immunized.

Pt.: $\quad$ Can't I also take the vaccine?

Doc.: No. Once you are hepatitis B positive, you cannot take the injection because you already have the disease. Before one gets the disease, one can get immunized. It's like giving a little dose of this virus in the - non-infective style. I don't know how to explain it. It's like when you immunize someone against TB. It's like giving a person a little dose of that infective substance so that the body should develop immunity against it.

Pt.: That's wonderful.

Doc.: So, that when the infection comes, the army in the body will quickly stand up against it and then kill it. Let her get tested. If she is negative, she gets immunized. If she is positive, nothing to lose.

Pt.: It is clear.

Doc.: So, the only thing I will do now is to give you a form for liver function test. Do it. There is no emergency in it. So, it's not as if you must do it now. I will give you a form and then you do it and bring it.

The doctor's emboldened contribution in the above extract revealed that the doctor threatened the patient's face by not mitigating her diagnosis as she unequivocally told the patient he could not take hepatitis B vaccine once he was infected with the ailment. She went a step further to educate the patient on the category of people that could take the vaccine as well as the method of administration and how it works. The doctor talked frankly to the patient on the impossibility of administering the vaccine on him to prove to him the incurability of hepatitis B. The discourse function of this facethreatening act was not just to give the patient accurate and truthful information about his ailment as demanded by medical ethics but also to sensitize him on the dangers of not getting the wife screened for the ailment. Therefore, the doctor did not mitigate the disclosure of the diagnosis to the patient.

\section{Extract 2}

BACKGROUND: Doc corrects Pt. who erroneously believes she suffers from hepatitis B.

Pt.: I have hepatitis B.

Doc.: Do you know what is called hepatitis B?

Pt.: I don't

Doc.: And you didn't bother to find out, unh? That is what is called hepatitis.

Pt.: I was not asked to come today. I did some tests and decided to bring the results today.

Doc.: $\quad$ Collects test result and reads it . This has nothing to do with what your complaint.] This test does not indicate any problem. Where did you do this? 
The doctor's emboldened contributions in the above extract constitute another instance of facethreatening act without redress in which the doctor slammed the patient's erroneous belief that she was hepatitis B positive. The doctor reaffirmed his claim with his third and fourth emboldened contributions in the extract, which is a true interpretation of the test result brought by the patient. The communicative function of this FTA is not just to reprimand the patient for holding the wrong notion but also to save the patient from undue emotional stress on account of untrue hepatitis B infection claim, which could spell a disaster for her health. The doctor, therefore, threatened the patient's face with no mitigation by censuring her for not finding out the true nature of her illness. FTA without redress was realized in each of the instances by declaratives.

\subsection{FTA With Redress (Positive Politeness): Correcting, Allaying Fears And Tactfully Obtaining Information For Diagnoses}

FTA with redress was realized by direct and indirect talk, mitigated threats and courteous expressions in the data. This study discovered that whether as a temporary or long term act the doctors threatened patients' face or minimized the threat to their face by not talking directly about their illnesses. Sometimes, this happens during clinical interviews following which doctors employ FTA with redress (Positive Politeness). At other times too, for reasons best known to doctors, patients' real medical problems are hidden from them. Most of the instances of FTAs with redress (positive politeness) available in the data presented as direct expressions, indirect expressions, courteous expressions and mitigated threats. We consider some instances here.

\section{Extract 3}

Pt.: I sometimes tell my wife that I have eaten when I am fasting.

Doc.: You don't need to tell your wife lies.

Pt.: I tell her lies because she worries about me too much.

Doc.: The issue is that if you take your drugs appropriately, you will live a quality life, you will live longer and she too will be happy. That's what her concern is all about.[Patient's wife calls.] She is the one calling you. I'm sure she wants you to be healthy. She wants to have you around her till grey hair comes out of your head. You understand. She knows your condition - health wise. Now, God knows your condition, so don't isolate your physical life from your spiritual. Both of you are together. If the doctor says 'Do not fast.' All you have to do is - you know there are other ways of fasting. Don't deny yourself food. Do you understand?

In the above extract, the doctor employed a polite expression to correct the patient's behaviour of telling lies to the wife. The doctor proved it was wrong for the patient to falsely admit he had eaten when asked by his wife simply because he was did not want her to know he was fasting. Thus, the doctor employed the FTA to correct the patient and educate him on the likely benefit of complying with medical instructions fully.

\section{Extract 4}

Doc.: How regularly do you take your drugs?

Pt.: I skip them sometimes?

Doc.: Why?

Pt.: Because I feel I am okay.

Doc.: Do you know that hypertension is not like malaria where you get treated, you get fine and you just go off it? That was why when you checked your BP two days ago, it was high.

Here, the doctor threatened the patient's face through polite expressions for violating medical prescriptions. Courteously, he drew the attention of the patient to the impropriety of skipping his drugs and the consequence of the wrong action. Grammatically, FTA with redress was realized by a combination of both declaratives and interrogatives in the data.

Politeness maxims are another aspect of the politeness phenomenon, and they are also germane to the analysis intended in this study. The politeness maxims observable in the interactions are the tact maxim, the generosity maxim, the sympathy maxim and the Pollyanna principle. They shall be discussed in turn. 


\section{TACT MaXim: COMPASSION AND PERMiSSION}

Realized by questions and statements, tact maxim was discovered to be observed in our data. The maxim states: Minimize cost to other, maximize benefit to other. Several of the doctors' utterances showed that they were considerate to the patients as they offered them the opportunity to gain maximum advantage in the hospital visits, even though such offers meant more work for them. We may consider the following extracts:

\section{Extract 5}

Doc.: Do you have any other medical condition you go to the doctor for?

Pt.: No.

\section{Extract 6}

Doc.: Is the pain very sharp?

Pt.: Yes.

Doc.: $\quad$ Examines the ear) There is a lot of wax blocking your ear. Let me see the second one. When you pick your ear with cotton bud, does the cotton bud go in? You have difficulty hearing well because wax has blocked the whole ear. So, you will buy serumol eardrop and apply it in the ear. After applying it in one ear, you should wait for five minutes to allow it go in very well before you apply it in the second ear. You will do it for two weeks and then come back for a review. Do you understand me? When you apply the eardrop, it will soften the wax and you will see it coming out. Then, we will refer you to E.N.T. clinic where the syringing of the ear will be done for you.

Pt.: $\quad$ Okay, sir.

Doc.: Let us apply it for two weeks and see. How I wish I got a better instrument. I would have removed a lot of the wax to enable you start hearing well again. The eardrop costs about \#800. You will apply it for two weeks. If it gets exhausted, buy another one till you have used it for two weeks.

Pt.: Thank you, sir.

Doc.: Bye bye.

In extracts 5 and 6 , the doctors' contributions showed that they were very compassionate on the patients and wanted them to derive maximum benefits from their visit to the hospitals. In Extract 5, the doctor offered the patient the opportunity to disclose other health problems he had so that he could treat them as well. Similarly, in Extract 6, the doctor's emboldened contribution suggested the doctor pitied the patient and would have assisted him by remove the wax that made it difficult for the patient to hear had it been the instrument for removing wax was available. Removing the wax would have meant more work for the doctor but she didn't mind. All these offers, no doubt, meant additional work for the doctors but they did not bother about them as the well being of the patients was paramount to them. Consequently, they were compassionate on the patients. Grammatically, the tact maxim was realized by interrogatives and declaratives.

\section{GENEROSITY MAXIM: ADVICE AND COMPASSION}

The generosity maxim performed the discourse function of advising the patients and showing them compassion in our data. Several times, the maxim was observed in the interactions between the doctors and patients as the doctors' minimized benefit to themselves and also maximized cost to themselves, too. Thus, the doctors showed concern for the patients' health. The following interactions may be considered:

\section{Extract 7}

Doc.: Next time when you are buying a toothbrush, make sure you look at the inscription on the packet because we have soft, medium and hard. Always use the medium one. It's the best for you. The soft is for children while the medium is for adult. Don't use the hard one because it damages your teeth. It scrapes off part of your teeth.

Pt.: Thank you. 


\section{Extract 8}

Doc.: The last time you came here was in June and this is November. Your blood pressure is always very high - 170/100. Do you take your drugs?

Pt.: Yes, I do.:

Doc.: Where are the drugs?

Pt.: They are in my bag.

Doc.: Bring them out. Let me see them. (Looks at the drugs) You need to pay a very good attention to your health because of the terrible conditions that may result from having untreated hypertension diabetes, stroke etc. You are not healthy yet you could go on visit to as far as Lagos. You need to come for check-up monthly.

Pt.: Thank you.

Doc.: We ask you to come once in a month, twelve times in a year. I do think this is too much a sacrifice for your health. Please, pay attention to your health.

Pt.: I I very grateful for your concern over my health. May God be with you.

Doc.: Even if you want to go on pilgrimage to Mecca, you should be able to carry your doctor along as he will be able to package you well by giving you drugs that could last you till you arrive. And immediately you come back, you go see him for a check-up. That way you will be able to maintain a good health.

Pt.: Thank you. I will be more careful next time.

In extracts 7 and 8 above, the doctors demonstrated great concern for the patients' health by offering them medically beneficial pieces of advice. In Extract 7, the doctor advised the patient to use the medium type of toothbrush to avoid the health risk inherent in the use of hard toothbrush. In Extract 8, the doctor advised the hypertensive patient on the importance of total adherence to medical prescriptions and instructions to avoid crises. In addition, the doctor stressed the importance of getting appropriately equipped with medicines whenever the patient is going on a long journey. Through the deployment of the generosity maxim in the doctors' contributions emboldened in the above extracts, the doctors were able to offer the patients some medically beneficial pieces of advice and at the same time demonstrate empathy. Grammatically, the generosity maxim was realized by declaratives and imperatives in the interactions.

\section{SYMPATHY MAXIM: AdVICE, PITY AND GUIDANCE}

Performing the communicative function of advice, pity and guidance, the sympathy maxim was seen to be observed in several interactions between the doctors and the patients, where the doctors empathised with the patients over certain terrible health conditions. Examples of some of the utterances made to observe the maxim are:

\section{Extract 9}

Doc.: What type of business do you do?

Pt.: Plastic.

Doc.: If I were to advise you in line with contemporary practice, three children are enough. God has given you both sexes. You see those of us that are educated, for example, the nurses and doctors, we stop childbearing after two issues, some even have just one. The three are enough. But if you still want to have more children, there is no problem. How many wives does your husband have?

Pt.: Two.

Doc.: Is it your husband that complaints the children are not enough or the family?

Pt.: I am the one that want more.

\section{Extract 10}

Doc.: Bring them out. Let me see them. (Looks at the drugs) You need to pay a very good attention to your health because of the terrible conditions that may result from having untreated hypertension - diabetes, stroke etc. You are not healthy yet you could go on visit to as far as Lagos. You need to come for check-up monthly. 
Pt.: Thank you.

Doc.: We ask you to come once in a month, twelve times in a year. I don't think this is too much a sacrifice for your health. Please, pay attention to your health.

Pt.: I I very grateful for your concern over my health. May God be with you.

Doc.: Even if you want to go on pilgrimage to Mecca, you should be able to carry your doctor along as he will be able to package you well by giving you drugs that could last you till you arrive. And immediately you come back, you go see him for a check-up. That way you will be able to maintain a good health.

Pt.: Thank you. I will be more careful next time.

In the above extracts, the doctors showed sympathy and empathy for the patients' health conditions and, therefore, counselled them on how best to handle their health in order to avoid crises. In Extract 9 , the doctor pitied the patient for her low economic status and consequently advised her to forgo the desire to have more children since she had had three issues already. The doctor employed this strategy to save the patient the financial agony associated with having more children than necessary.

In Extract 10, the doctor was compassionate on the hypertensive patient and thus advised him to pay more attention to his health to avoid complications like - diabetes and stroke- that could result from untreated hypertension. He enlightened the patient on how he could go on a long journey and yet be adequately medically equipped for such a trip.

\section{Pollyanna Principle}

The Pollyanna principle was also observed in the examined verbal medical interactions. It enjoyed the greatest frequency of use. Its frequent occurrence shows that verbal medical discourse focuses more on the positive than the negative aspect of life. This phenomenon emanates from the contextual beliefs based on medical ethics and those based on the patients- society's perspective of doctors. Medical ethics demand that doctors directly or indirectly use their professional skills to treat patients and not to harm them either psychologically or physically. Conversely, patients too expect that doctors will meet their medical, physical and emotional desires. The Pollyanna principle has three tendencies, namely: euphemistic tendency, ethical positivity tendency and referential/hinting tendencies, but only the ethical positivity tendency was found to characterize the interactions studied.

\subsection{The Ethical Positivity Tendency: To Open Up Talks}

Pollyanna principle of ethical positivity echoes the ethical expectations of doctors to patients, particularly in the area of medical care, assurance, reassurance, sympathy etc. It has to do with the contextual beliefs based on the patients-society's view of the doctors. The hospital is an orthodox institution viewed by the patients and the larger society as a home of relief and cure. The patients regard the doctors as health problem solvers. Thus, they hold the doctors in very high esteem as people that can be confided in. The medical profession also recognizes this:

Secrecy is sacred to the profession. It is essential a patient tells you

Everything you for diagnosis and treatment.... in cases of unwanted pregnancy, veneral disease for instance, he or she naturally and instinctively does not want it spread. It is not for you to tell it to anyone - not even to a husband or wife or brother or sister-in law. (Mabayoje, 1982 p.11 cited in Odebunmi, 2003)

It should be noted however that some patients advertently conceal certain information from doctors for some reasons best known to them. All patients believe they would get sufficient care and kind attention from doctors. Consequently, most of them open up on their medical problems to doctors in anticipation of cooperation from doctors. Our data contain instances of this phenomenon:

\section{Extract 11}

Doc.: Were you ever diagnosed with diabetes or hypertension?

Pt.: Diabetes

Doc.: Where do you treat it and what drugs are you taking to cure it?

Pt.: The drugs I was given are in my bag. 


\section{Extract 12}

Pt.: I cannot menstruate again.

Doc.: You are the one that can tell us if it has stopped.

Pt.: Enh. I no longer menstruate.

Doc.: Do you still have sex with your husband? It has stopped.

Pt.: Yes.

As can be seen in Extracts 11 and 12 above, the deployment of the ethical tendency positivity enabled the patients to freely explain their health challenges because they had the confidence that the doctors could treat them. Consequently, the doctors also reciprocated the patients' display of confidence in their professional capabilities by either recommending one type of test or another or prescribing some drugs to treat them. It performed the communicative function of enabling the patients to lay bare all their health challenges. Grammatically, the ethical positivity tendency was realized by declaratives and single words.

\section{FindingS AND CONCLUSIONS}

The study has revealed that politeness is a very useful communication tool for both doctors and patients as it enabled them to facilitate the discourse. The deployment of the face-threatening acts and the politeness maxims afforded the doctors the opportunity to check and correct the patients' unwholesome practices, allay their fears and tactfully obtain information for diagnosis; give advice and express compassion to make the discourse result-oriented. The various politeness elements perform a number of communicative functions. FTA with redress corrects unwholesome health practices; FTA without redress tactfully obtains medical data for diagnosis; tact maxim expresses compassion; generosity maxim offers advice; sympathy maxim offers guidance, and the ethical positivity tendency opens up talks. Knowledge of these elements of politeness and their discourse functions are therefore crucial to a better comprehension of clinical discourse in Nigeria.

\section{REFERENCES}

[1] Bousfield, D., \& Locher, M. A. (2008). Impoliteness in language. Studies on its Interplay with Power in Theory and Practice. Berlin (Mouton de Gruyter).

[2] Eelen, G. (2001). A critique of politeness theories. Manchester: St. Jerome.

[3] Grice, H. P. (1975) Logic and conversation. P. Cole \& J. L. Morgan (eds.), Syntax and Semantics. New York: Academic Press, pp. 41-58.

[4] Fraser, B. (1990). Perspectives on politeness. Journal of Pragmatics, 14(2), 219-236.

[5] Gorji, M. (2007). Rude Britannia. London: Routledge.

[6] Kasper, G. (1990). Linguistic politeness. Journal of Pragmatics: Current Research Issues. 14(2), 193218.

[7] Lakoff, R. T. (1973). The logic of politeness, or minding your p's and q's. Chicago Linguistics Society, 9, 292-305.

Leech, G. N. (1983): Principles of pragmatics. New York: Longman.

[8] Martin, G. 2014. "Medical discourse and pragmatics." Klaus P. Schneider and Anne Barron (eds) Pragmatics of discourse. Pp. 491-524. Berlin/Boston: Walter de Gruyter GmbH.

[9] Mills, S. (2005). Gender and impoliteness. Journal of Politeness Research, 1(2), 263-280.

[10] Odebunmi, S.A. (2003). Pragmatic features of English usage in hospital interactions amongst medical practitioners and patients in South-Western Nigeria. Unpublished Doctoral dissertation. University of Ibadan. Nigeria.

[11] Sarangi, S. \& Roberts, C. (1999). The dynamics of interactional and institutional orders in work- related settings. Srikant Sarangi and Cecilia Roberts (eds.) Talk, work and institutional order: discourse in medical, meditation and management settings. Pp. 1-57. Language, power and social process 1). Berlin/New York: Mouton De Gruyter. Thomas, J. 1995. Meaning in interaction: an introduction to pragmatics. New York: Longman.

[12] Watts, R. J. (1989). Relevance and relational work: linguistic politeness as politic behaviour. Multilingua, $8(2-3), 131-166$ 
Politeness and Discourse Functions in Doctor-Patient Verbal Interactions at the University College Hospital, Ibadan, Nigeria

[13] Watts, R. J. (1992). Linguistic politeness and politic verbal behaviour: reconsidering claims for universality. R. J. Watts, S. Ide \& K. Ehlich (eds.), Politeness in language: studies in its history, theory and practice. Berlin / New York: Mouton de Gruyter, 43-69.

[14] Yule, G. (1996). Pragmatics. Oxford: Oxford University Press.

Citation: Adewale Kazeem Ayeloja \& Taofeek Olanrewaju Alabi. "Politeness and Discourse Functions in Doctor-Patient Verbal Interactions at the University College Hospital, Ibadan, Nigeria". International Journal on Studies in English Language and Literature (IJSELL), vol 6, no. 12, 2018, pp. 1-12. doi: http://dx.doi.org/10.20431/2347-3134.0612001.

Copyright: (C) 2018 Authors. This is an open-access article distributed under the terms of the Creative Commons Attribution License, which permits unrestricted use, distribution, and reproduction in any medium, provided the original author and source are credited. 